\title{
Acquired Monocular Vision Rehabilitation program
}

\author{
Carolyn Ihrig, OD; ${ }^{1-2 *}$ Daniel P. Schaefer, MD, FACS ${ }^{3-4}$ \\ ${ }^{1}$ Buffalo Department of Veterans Affairs Medical Center, Buffalo, NY; ${ }^{2}$ Department of Ophthalmology, Division of \\ Low Vision, ${ }^{3}$ Department of Otolaryngology, and ${ }^{4}$ Department of Ophthalmology, Division of Oculoplastic, Orbital \\ Plastics and Reconstructive Surgery, Ira G. Ross Eye Institute, University at Buffalo School of Medicine and Biomedical \\ Sciences, The State University of New York, Buffalo, NY
}

\begin{abstract}
Existing programs concerning patients with low vision do not readily meet the needs of the patient with acquired monocular vision. This article illustrates the development, need, and benefits of an Acquired Monocular Vision Rehabilitation evaluation and training program. This proposed program will facilitate the organization of vision rehabilitation with eye care professionals and social caseworkers to help patients cope with, as well as accept, and recognize obstacles they will face in transitioning suddenly to monocular vision.
\end{abstract}

Key words: acquired monocular vision, acquired monocular vision rehabilitation, cognitive function, depression, independence, loss of depth perception, monocular motility skills, motor development, nasal or temporal occlusion, neuro-optometric rehabilitation, polycarbonate lenses, prisms, supportive counseling, traumatic brain injury, visual field defects, visual rehabilitation.

\section{INTRODUCTION}

Sudden loss of sight in one eye or the loss of an eye often necessitates immediate and extensive medical and psychological intervention. From this loss, patients will experience sudden loss of depth perception, decrease of visual field and, most frequently, depression. Mary P. Coday, MD, and colleagues surveyed a variety of patients with acquired monocular vision [1]. Their survey consisted of 30 questions. Of the 65 respondents, 91 percent stated that they had no formal training to help them adapt to their sudden vision loss [1]. Most believed that training to help with the adjustment to the loss of depth perception, training on safety and social concerns, and supportive counseling would have been beneficial [1].

Currently, low-vision rehabilitation programs are available for the partially sighted, such as those suffering from macular degeneration, but they do not readily meet the needs of the patient with acquired monocular vision. The survey just noted inspired the development of the Acquired Monocular Vision Rehabilitation (AMVR) evaluation and training program to guide and teach these specific skills to each patient with acquired monocular vision. This program maximizes the remaining monocular vision of the patient by teaching visual skills to acquire and maintain independence and prevent depression.

The loss of an eye or the total loss of sight in one eye may be secondary to a multitude of injuries our troops sustain during battle but continues to occur frequently despite their use of protective eye wear. When compared with other rehabilitation services for injuries resulting in systemic physical disabilities secondary to trauma, such as the loss of a limb, vision rehabilitation for loss of

\footnotetext{
Abbreviation: AMVR = Acquired Monocular Vision Rehabilitation.

* Address all correspondence to Carolyn Ihrig, OD; Buffalo Department of Veterans Affairs Medical Center, 3495 Bailey Avenue, Buffalo, NY 14215; 716-862-7843. Email: carolyn.ihrig@va.gov or cihrig@buffalo.edu DOI: 10.1682/JRRD.2006.06.0071
} 
depth perception and decrease in peripheral visual field is frequently not addressed at the initial_or latter stage of these rehabilitation services. Appendix 1 (available online only at http://www.rehab.research.va.gov/) is a survey designed to be given to patients at a trauma center. Its design was influenced by Coday et al.'s survey [1], and it identifies those individuals who need and have the ability to proceed with evaluation and subsequent vision rehabilitation.

This article describes the AMVR evaluation and training program for all individuals who have newly acquired monocular vision. This program organizes vision rehabilitation, eye care professionals, and social caseworkers to help patients cope with the obstacles they face when suddenly transitioning to monocular vision. It consists of-

- A comprehensive history, including goals and concerns.

- A thorough evaluation, including refraction, safety lenses, and monocular ocular motility skills training.

- Home adaptive skills and mobility training to help each patient compensate for their sudden decrease in visual field and loss of depth perception.

\section{COMPREHENSIVE HISTORY}

Patients' general information is obtained and evaluated Appendix 2, available online only at http:// www.rehab.research.va.gov/), including information regarding current treatment with their ophthalmologist, which will vary depending on the etiology of the loss (secondary to trauma, tumor, glaucoma, infection, etc.). The dates of their visual loss and/or removal of their eye if applicable are noted. Ideally, patients should be referred to a social caseworker to help them emotionally deal with the sudden initial trauma or loss. If the diagnosis results in the scheduling of an eye to be enucleated, a social caseworker helps prepare the patient emotionally for the sudden change.

Each patient is assessed in several areas. The visual acuity and visual field of the patient's remaining eye may be normal or reduced and should be maximized. Is the patient dealing with the loss of the dominant eye, which may complicate the adaptation process more? Some patients may need a prosthetic eye, scleral shell, or cosmetic contact lens and must be instructed and prepared to adjust to its care, use, and insertion techniques. Patients' general health history is noted along with a list of their current medications. Each person's psychological reaction to his or her loss will also vary. As soon as the patient enters the room, the physical examination starts. The patient's entry is important to observe. Does the patient walk naturally through the doorway to the examination chair or is he or she hesitant? Does the patient bump into the doorway? Is the patient's personality outgoing or is he or she neutral or withdrawn?

Next, the patient is asked about any difficulty with mobility. Does the patient walk outdoors alone and continue to drive? Does the patient have difficulty with steps, stairs, and curbs? Does the patient bump into people or cut them off when walking? If he or she answers "yes" to any of these questions, the difficulty should be noted as mild, moderate, or severe.

Distance vision (e.g., watching television) and illumination and glare issues are also addressed. Questions regarding near vision address (1) fatigue while reading, (2) losing one's place while reading, and (3) spilling liquids when pouring.

In addition, current employment and hobbies are addressed as to each specific task and noted if difficulty is mild, moderate, or severe. Other concerns such as patients' cosmetic appearance, their ability to perform in sports, and their ability to perform in their working environment are also addressed.

\section{EVALUATION}

External examination, confrontation visual field, color vision, refraction, slit lamp, ophthalmoscopy, tonometry, and the comprehensive eye examination are performed on each patient. Spectacle prescriptions are recommended as needed for improving distance and near vision. Polycarbonate lenses and sports goggles are always prescribed for the safety of all patients, whether they have a refractive error or not.

According to Coday et al.'s survey noted earlier, 19 percent of patients reported difficulty reading after losing vision in one eye [1]. Fatigue while reading and losing their place while reading were also noted [1]. Prescribing reading glasses for nonpresbyopic patients should be considered, and symptoms of fatigue should be monitored.

Traditional vision training exercises for binocular patients who show deficiencies with accommodation, saccades, and pursuits have produced positive changes in visual functioning [2-10]. The sequential visual training 
regimens are administered monocularly first, then biocularly (unfused), and finally binocularly [10]. According to C. F. Gruning, "motility skills are developed first (pursuits, saccades, and eye-hand coordination), then accommodation (sustaining facility, speed, awareness, and comfort), and then fusion (vergence amplitude and vergence facility)" [10]. Consequently, if patients with monocular vision note that they often lose their place while reading, various eye movements are tested for evaluating the efficient use of their eye, including monocular saccades, pursuits, and near-to-far accommodation. If needed, home ocular motility skills training is given. This training incorporates saccadic eye movements and near-to-far focusing skills to reduce difficulty while reading [6] Appendix 3, available online only at http://www.rehab.research.va.gov/, is one example of saccadic eye-movement training using a Hart Chart $^{\mathbb{C}}$ [Dr. Walter Hart, Tacoma, Washington]).

\section{HOME ADAPTIVE SKILLS AND MOBILITY TRAINING}

General routine skills in the home become more difficult because of the loss of depth perception and decrease in peripheral visual field [11-15]. One example of a general skill is pouring liquids in a glass. In training, the patient is instructed to use a clear cup when pouring darker fluids and to use darker cups when pouring lighter colored fluids. This exercise teaches the patient to use contrast as a guide instead of depth perception. Other pouring exercises have the patient move a pitcher in a direct line until the patient touches the upper container (pitcher) to the rim of the lower container (cup). The same technique is demonstrated when a spoon is used to add contents to a cup.

The loss of one eye will result in a 10 to 20 percent decrease in the horizontal visual field [16]. The patient is instructed to increase the range of horizontal eye movement of the remaining eye frequently and also to increase head movement to compensate for the sudden visual field decrease. The patients are taught to observe varying angles and the apparent change in size of objects as they move toward or away from an whect which toaghes them to use relative motion [14-20] Appendixes 4-5, available online only at http://www.rehab.research.va.gov/, are two examples of training exercises).

One can use relative motion as a cue to judge depth within 20 feet without having depth perception. For example, a patient is asked to look at two stationary objects at varying distances and laterally displace his or her head from side to side and observe the relative motion of the background. If he or she observes the background moving more (relatively) when looking at object 1 compared with looking at object 2, object 1 is closer. Conversely, if the patient observes less relative motion of the background when looking at object 2, then object 2 is farther away $[14,16-17,19]$. Color changes will occur at different distances, and these changes are also demonstrated. Brighter and bolder colors are closer, and softer and muted colors are in the distance [16].

An object observed moving toward you is observed as increasing in size and moves in a straight line. A moving object observed as moving at a continuous increasing angle is traveling toward your side. Nerf ${ }^{\mathrm{TM}}$ balls (Hasbro Inc, Pawtucket, Rhode Island) are used for demonstration $[16,18,20]$. (See Appendix 4 for an example of exercises using Nerf balls.)

Eye-hand-coordination exercises can be fun when various examples are used. Games that incorporate reaching for objects teach the patients with monocular vision to keep moving their hands in a direct line toward the object until they connect to the object, such as a doorknob, a book on the shelf, a cup on the counter, or a friendly handshake [16]. Playing checkers and pick-up sticks are also good practice techniques that optimize monocular eye-hand coordination.

Mobility is another area that is affected by the loss of depth perception. Accurately judging distances and maneuvering around chairs and tables, walking up steps and curbs, crossing the street, etc., are extremely important for safety. Teaching mobility training to patients with monocular vision maximizes their reduced visual field by having them turn their heads to scan the area of loss more frequently and farther than was previously needed [16]. The important point to emphasize to the patient is to turn his or her head before changing direction suddenly [16] Appendix 6, available online only at http://www.rehab.research.va.gov/).

Mobility exercises include an individual (or therapist) walking on the side of the patient's seeing eye and then shifting to the side of the patient's nonseeing eye [16]. The patient practices moving his or her head to see the person or slows down and lets the person pass to the side of his or her seeing eye [16]. A small unbreakable mirror can be held on the side of the nonseeing eye. When the mirror is tilted slightly (at a small angle), the side viewing area can be increased when needed. (See the Figure for an exercise designed to demonstrate an increase in viewing area.) The unbreakable mirror can also be attached to strategic areas of 


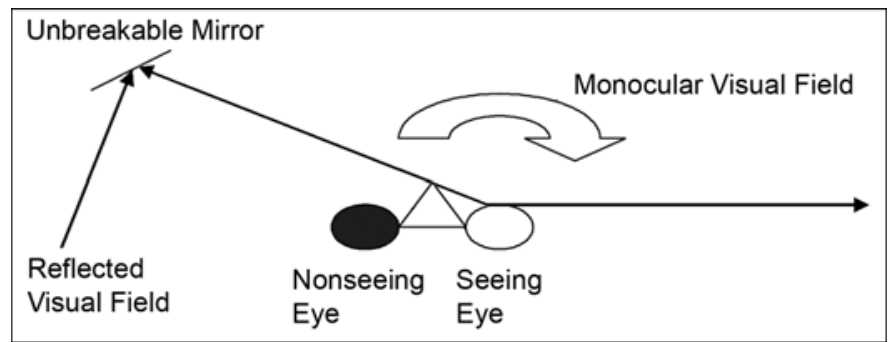

Figure.

Illustration of potential increase in peripheral visual field by reflected image of small unbreakable mirror held on side of nonseeing eye. When patient tilts mirror slightly (at a small angle), side viewing area can be increased when needed to compensate for visual field defect of nonseeing eye.

the windshield of an automobile, without obstructing vision, to compensate for the visual field defect of the nonseeing eye while the person is driving.

Patients with monocular vision are instructed that when they are sitting at a table or in a living room with another person, they should try to position themselves so that the other person is sitting on the side of the seeing eye. They should always look toward the direction of the nonseeing eye before gesturing or moving in that direction, especially at a restaurant, since food servers may approach the patient from the side of the nonseeing eye.

Walking up and down steps is also demonstrated. Patients are taught to hold onto the handrail and watch for the last step by feeling ahead with their toes. They are shown how to walk toward curbs by keeping their eyes on the edge of the curb as they approach it. As they laterally displace their heads from side to side, patients are also taught to observe that the relative motion against the background of the street's surface will increase when the curb is higher and will decrease when the curb is lower [14,16-17,19].

Patients are also trained to look both ways before and at the last moment just before attempting to cross the street. They are also made aware of one-way streets and street corners where automobiles can either turn right or left. Driving tips should also be discussed [16] Appendix 7, available online only at http://www.rehab.research.va.gov/).

The difficulty of revolving doors are also demonstrated. For safety reasons, patients are advised to avoid these when possible and simply use the stationary side doors.

Although not addressed in this AMVR training program, rehabilitation therapy can also be expanded to include neuro-optometric rehabilitation if the patient has also suffered neurological involvement of the visual system secondary to the multitude of entities that can involve the central nervous system, such as traumatic brain injury [21-25]. Because of the major impact that disease or trauma can have on the visual system, which is secondary to the interconnections with the cognitive and motor systems, a patient's balance, coordination, and motility will also be affected [21-25]. When needed, prisms and nasal or temporal occlusion may be integrated and monitored in all aspects of the rehabilitation program [21-25].

\section{CONCLUSIONS}

This AMVR evaluation and training program is designed to begin helping patients with acquired monocular vision adapt and cope with this sudden change in their vision. Using new skills that maximize their current visual status compensates for patients' loss of depth perception and decrease in visual field, as well as supports and encourages each person to practice these skills each day.

Maintaining independence and preventing depression are challenging efforts. Along with social caseworkers to help patients cope emotionally, this process of demonstrating new adaptive techniques and exercises shows that each person "is-able” and not "dis-abled."

\section{ACKNOWLEDGMENTS}

This material was unfunded at the time of manuscript preparation.

The authors have declared that no competing interests exist.

\section{REFERENCES}

1. Coday MP, Warner MA, Jahrling KV, Rubin PA. Acquired monocular vision: functional consequences from the patient's perspective. Ophthal Plast Reconstr Surg. 2002;18(1):56-63. [PMID: 11910326]

2. Ciuffreda KJ. The scientific basis for and efficacy of optometric vision therapy in nonstrabismic accommodative and vergence disorders. Optometry. 2002;73(12):735-62. [PMID: 12498561]

3. Hoffman L, Cohen AH, Feuer G. Effectiveness of nonstrabismus optometric vision training in a private practice. 
Am J Optom Arch Am Acad Optom. 1973;50(10):813-16. [PMID: 4520500]

4. Kulp MT, Schmidt PP. Effect of oculomotor and visual skills on reading performance: a literature review. Optom Vis Sci. 1996;73(4):283-92. [PMID: 8728497]

5. Wold RM, Pierce JR, Keddington J. Effectiveness of optometric vision therapy. J Am Optom Assoc. 1978;49(9): 1047-54. [PMID: 701721]

6. Rounds BB, Manley CW, Norris RH. The effect of oculomotor training on reading efficiency. J Am Optom Assoc. 1991;62(2):92-99. [PMID: 1814996]

7. Rouse MW. Management of binocular anomalies: efficacy of vision therapy in the treatment of accommodative deficiencies. Am J Optom Physiol Opt. 1987;64(6):415-20. [PMID: 3307438]

8. Bobier WR, Sivak JG. Orthoptic treatment of subjects showing slow accommodative responses. Am J Optom Physiol Opt. 1983;60(8):678-87. [PMID: 6624867]

9. Hung GK, Ciuffreda KJ, Semmlow JL. Static vergence and accommodation: population norms and orthoptics effects. Doc Ophthalmol. 1986;62(2):165-79. [PMID: 3956367]

10. Gruning CF. Clinical management of nearpoint stressinduced vision problems. Am J Optom Physiol Opt. 1985; 62(6):386-91. [PMID: 4014426]

11. Knill DC. Reaching for visual cues to depth: the brain combines depth cues differently for motor control and perception. J Vis. 2005;5(2):103-15. [PMID: 15831071]

12. Marotta JJ, Behrmann M, Goodale MA. The removal of binocular cues disrupts the calibration of grasping in patients with visual form agnosia. Exp Brain Res. 1997; 116(1):113-21. [PMID: 9305820]

13. Dijkerman HC, Milner AD, Carey DP. The perception and prehension of objects oriented in the depth plan. I. Effects of visual form agnosia. Exp Brain Res. 1996;112(3):442-51. [PMID: 9007546]

14. Reinhardt-Rutland AH. Remote operation: a selective review of research into visual depth perception. J Gen Psychol. 1996;123(3):237-48. [PMID: 8953235]
15. Collett TS, Schwarz U, Sobel EC. The interaction of oculomotor cues and stimulus size in stereoscopic depth constancy. Perception. 1991;20(6):733-54. [PMID: 1816533]

16. Brady FB. A singular view: The art of seeing with one eye. 5th ed. Annapolis (MD): Frank B. Brady (self-published); 1994.

17. Bradshaw MF, Rogers BJ. The interaction of binocular disparity and motion parallax in the computation of depth. Vision Res. 1996;36(21):3457-68. [PMID: 8977012]

18. McCready D. On size, distance, and visual angle perception. Percept Psychophys. 1985;37(4):323-34. [PMID: 4034350]

19. Cutting JE, Vishton PM. Perceiving layout and knowing distances: The integration, relative potency, and contextual use of different information about depth. In: Epstein W, Rogers S, editors. Handbook of perception and cognition, Vol 5: Perception of space and motion. San Diego (CA): Academic Press; 1995. p. 69-117.

20. Gogel WS, Eby DW. Measures of perceived linear size, sagittal motion, and visual angle from optical expansions and contractions. Percept Psychophys. 1997;59(5):783-806. [PMID: 9259645]

21. Kapoor N, Ciuffreda KJ. Vision disturbances following traumatic brain injury. Curr Treat Options Neurol. 2002;4(4): 271-80. [PMID: 12036500]

22. Padula WV, Argyris S. Post-trauma vision syndrome and visual midline shift syndrome. NeuroRehabilitation. 1996; 6:165-71.

23. Cohen AH. Optometric management of binocular dysfunctions secondary to head trauma: case reports. J Am Optom Assoc. 1992;63(8):569-75. [PMID: 1512408]

24. Padula WV, Shapiro J. Post-trauma vision syndrome caused by head injury. Neuro-Optometr Rehabil. 1996;179-93.

25. Padula WV. Visual midline shift syndrome. J Low Vis Neuro Optom Rehabil. 1997;11(1):22-23.

Submitted for publication June 19, 2006. Accepted in revised form February 28, 2007. 